\title{
Assessing the Use of Government Open Data and the Role of Data Infomediaries: The Case of Nova Scotia's Community Counts Program
}

\section{Mavis Chan}

Nova Scotia Community Counts, Government of Nova Scotia Department of Finance and Treasury Board, 1723 Hollis Street, Halifax, Nova Scotia. E-mail/phone: m58chan@uwaterloo.ca, +902-424-2740 Faculty of Environment, University of Waterloo, 200 University Avenue West, Ontario, Canada. Email/phone: m58chan@uwaterloo.ca

\section{Peter A. Johnson}

Department of Geography and Environmental Management, University of Waterloo, 200 University Avenue West, Ontario, Canada. E-mail/phone: peter.johnson@uwaterloo.ca, +519-888-4567 Ext. 33078

\section{Malcolm Shookner}

Nova Scotia Community Counts, Government of Nova Scotia Department of Finance and Treasury Board, 1723 Hollis Street, Halifax, Nova Scotia. E-mail/phone: malcolm.Shookner@novascotia.ca, +902-424-3247

Abstract: This study provides a retrospective evaluation of the Nova Scotia Community Counts program, a common platform where aggregated data from many sources mirrors what is generally considered as government open data. The role of Community Counts as a data infomediary added additional value for both data providers and users within informationintensive open data ecosystems. While data literacy is a recurring issue in the open data world, Community Counts should be considered a successful case for engagement with open data, serving as a catalyst to improve data literacy. This study also reveals the importance of harnessing the social benefits of open data, as it provides additional incentive for users to engage in data, thereby increasing open data usage and allowing further value to be realized by a more diverse base of users.

Keywords: open data, data literacy, infomediary, open governance, data use empowerment

\section{Introduction}

Open data consists of government data that is free for the public to access, use, modify, and share (Bonina, 2013; Open Knowledge, 2015). The value of open data can be defined to include economic, 
social, political, and technical areas (Janssen et al., 2012). Economic benefits are often considered as a main driver that encourages government open data, including reduction of data transaction costs, economic growth spurred by data availability, job creation, and increased tax revenue through improved efficiencies (Granickas, 2013). Other benefits include better service provisions to meet individual and community demands, overall increased government transparency, and advancing citizens' rights to access of information (Zuiderwijk \& Janssen, 2013; Veljković et al., 2014). Open data promotes governance that is "smarter, faster, and better" (Nam \& Pardo, 2014) and aligns with a trend seen around the world of moving towards a culture of greater government openness and transparency. For example, in Canada, the Federal government launched an open data portal alongside an Open Government Strategy with the objective to "maximize the release of government information and data of business value to support transparency, accountability, citizen engagement, and socio-economic benefits through reuse, subject to applicable restrictions associated with privacy, confidentiality, and security." (Treasury Board of Canada, 2012; Treasury Board of Canada, 2014). This development is part of a wider drive in Canadian government to open public-sector data, as open data portals have been established in many provinces and largest cities (Roy, 2014; Currie, 2013). These initiatives show a growing trend of governments adopting open data initiatives and open government policies.

As open data initiatives are emerging in diverse environments around the world, the uniqueness in context of individual initiatives has resulted in a lack of standardization in both the development and assessment of open data platforms (Caplan et al., 2014; Charalabidis, Loukis, \& Alexopoulos, 2014). As identified by Veljković et al. (2014), assessment of open data programs is important to ensure that goals are met and that continual improvements are made. Evaluating open data programs can optimize their emerging and not yet fully known benefits, determine the economic and social impacts of open data, improve the quality of open datasets available, prioritize the availability of datasets, and provide justification for more open data to be provided. Additionally, evaluation can provide important insight on the factors that lead to successful open data initiatives. Calplan et al. (2014) synthesize various methods through which open data can currently be assessed. Country-ranking open data assessments include initiatives such as The Open Data Barometer (2015), which measures the progress of open data projects at the national level in 77 countries around the world using indicators of open data readiness, implementation, and impact. Similarly, the Open Data Index \& Open Data Census assesses government progress on making key datasets available for 70 countries. In 2013, the Open Data Index provided an overall score of open data progress from measuring the technical and legal openness of various types of datasets. The European PSI (2015) also measures the status of open data projects based on various categories, including implementation of a PSI directive, practice of re-use, format, pricing, exclusive arrangements, availability of local public service information, events and activities (The European Public Sector Information Board, 2015). The OECD Framework suggests an analytical framework for national open data portals with criteria similar to the Open Data Barometer and Open Data Index (Ubaldi, 2013), but includes a focus on legal, technical, and organizational openness. Although the framework has not been applied, this latter criterion supports the importance of measuring the extent in which governments have empowered employees to adopt a culture of openness. 
In deriving value from open data, focus is often placed on how third parties (i.e., those using, not generating, the open data) enhance or add value to government open data. As open data is often considered a potential driver of innovation and economic benefit, the role of open data users such as government, citizens, businesses, entrepreneurs, non-profits, and other stakeholders, in enhancing raw data, becomes an important area of study (Granickas, 2013; Veljković et al., 2014). These users of open data often occupy a position that can be termed an "infomediary", that is, an entity that uses open data produced by a government to deliver a service or information to a target audience (Davies, 2010; Janssen \& Zuiderwijk, 2014). In this way, an infomediary does not generate open data, but rather extracts added value from it through manipulation, combination, visualization, or analysis, creating information directed at a set of end users (Davies \& Edwards, 2012; Janssen \& Zuiderwijk, 2014). For example, businesses and entrepreneurs that use open data to provide innovative products and services, including both technology applications and efficiency improvements in systems, are acting as an infomediary (Granickas, 2013). Similarly, a community group or NGO that uses government open data to prepare a report to its membership on a local issue is acting as an infomediary. Without infomediaries, open data is often opaque and fails to serve its purpose of providing value-add to the non-expert.

The goal of this research is to assess and reflect on the impact of ten years of government provision of public information, in this case the Canadian province of Nova Scotia's provision of community-level statistics data and information though the Community Counts program, recently closed due to budget reallocation (http://www.novascotia.ca/finance/communitycounts/). This research aims to assess not only the program itself, but also to contextualize its role as that of an open data infomediary, and provide a summary of the outcomes of the program that can serve as a guide for the current generation of open data programs. We determine whether infomediaries play a key role in enabling open data use and allowing society to recognize its full economic value. With the variety of approaches to evaluating national-level open data programs, it is important to recognize that much data provision, and especially data use, occurs at the local level. This case study can provide a comparison to existing initiatives, add value to the emerging field of open data assessment, and provide a deeper understanding of the role of open data infomediaries. Assessment methods utilized throughout the analysis of this study also provide guidelines for future assessment studies.

\section{Case Study Description and Method}

\subsection{The Nova Scotia Community Counts Program}

Nova Scotia Community Counts was a program administered by the Nova Scotia Department of Finance and Treasury Board from 2005 until its recent closure in mid-2015 due to government restructuring and reallocation of economic development resources. The objective of Community Counts was to provide statistical information on Nova Scotian communities and 15 other levels of geography, e.g., municipalities, school boards, district health authorities and watersheds. Nova Scotia is Canada's easternmost mainland province, with a population of approximately 942,700 in 
2014 (Statistics Canada, 2014). For over a decade, Community Counts provided a common platform for data from many sources that mirrored what is generally considered as government open data. Data on the Community Counts website was compiled from Statistics Canada, Canada's federal statistics agency, which includes the Census of the Population (1991-2011) and National Household Survey (2011), Canadian Centre for Justice Statistics, Canadian Community Health Survey, Labour Force Survey, and tax-filer data. The Census of the Population and the National Household Survey are questionnaires compiled by Statistics Canada to construct a statistical portrait of the Canadian population (Statistics Canada, 2015). The Census, a mandatory questionnaire on demographics disseminated on a quinquennial basis to all Canadians, was replaced by the National Household Survey in 2011 which is voluntary in nature ${ }^{1}$. Data on the Community Counts website was provided for free, and also derived from various sources within the Government of Nova Scotia. An example of a Community Counts dataset can be seen in Figure 1 below. The figure illustrates population by five-year age group on the Cape Breton Region Municipality of Nova Scotia. The Community Counts website also contained a tool called the Map Centre, consisting of up to 40,000 maps that can be custom generated for users to view data and up to 75 community assets.

Community Counts was used by government, business, community groups, non-profit organizations, colleges and universities, and the broader public. It assisted users with activities such as policy development, program evaluation, community planning, and decision-making. Over Community Counts' ten-year operation, many training sessions have been held across the province, with over 500 individuals having taken Community Counts training and many more accessing the website. As a single-point information source, it provided stakeholders with a reliable source of data, accessible in a timely and efficient manner. Similar to other open data initiatives developing across other Canadian governments, Community Counts provided an information source that is open for the public to use, reuse, and redistribute without charge. To evaluate the impact of Community Counts, an online user survey and key informant interviews were conducted. Conclusions and recommendations resulting from the analysis were used to assess the value and impact of Community Counts within its community of users.

\footnotetext{
${ }^{1}$ The Census short form, distributed to all households, requires a response about basic demographic information for each member of the household: age, sex, and family structure. The former Census long form, distributed to a $20 \%$ sample of all households, required responses to a range of questions aboriginal identity, citizenship and immigration, ethnicity, mobility, languages, religion, and visible minorities. It was replaced in 2011 with the National Household Survey, which was distributed to a 30\% sample of all households, with a request to fill in voluntarily.
} 


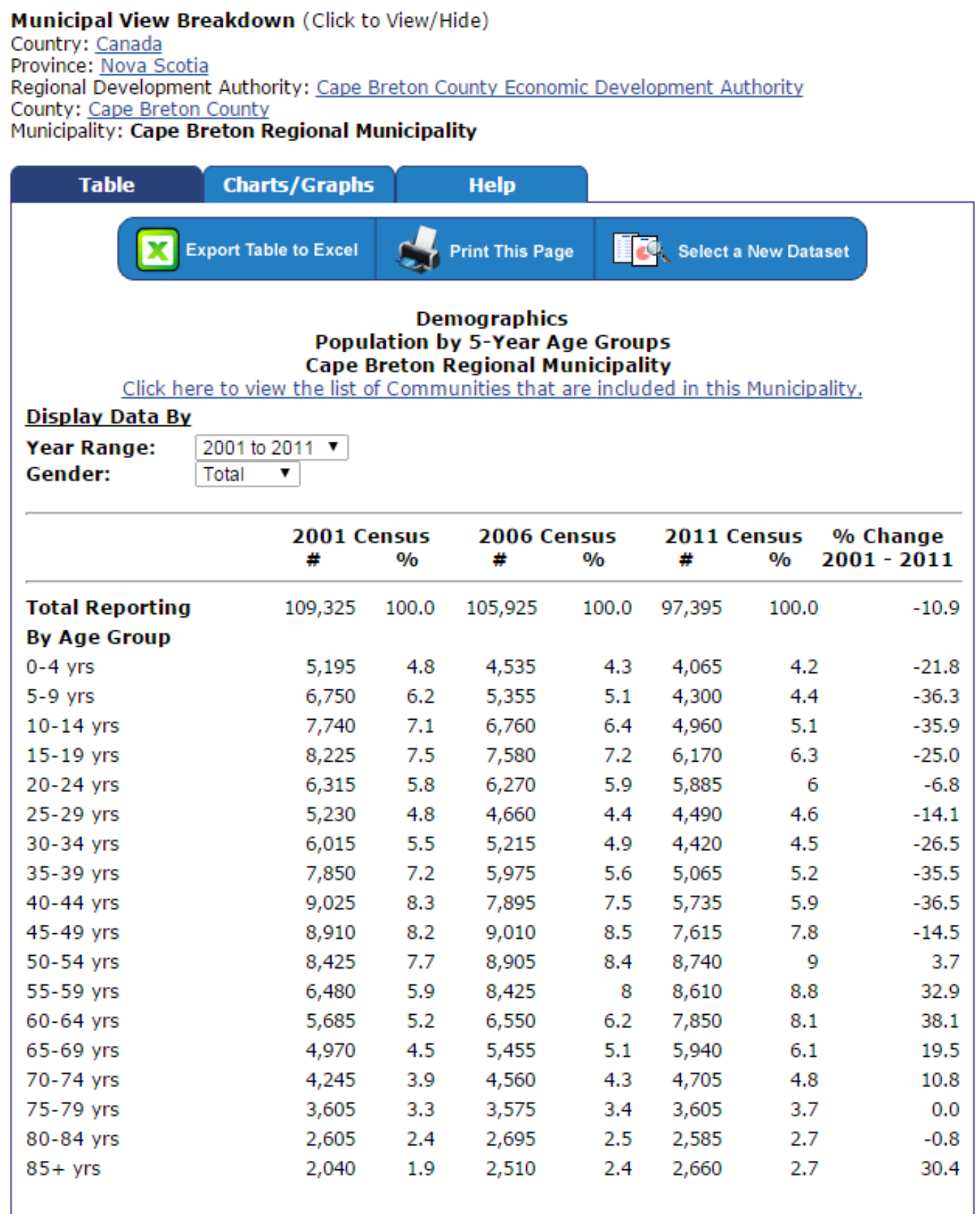

Figure 1: Example of Community Counts' datasets illustrating population by five-year age group

\subsection{Data Collection}

The Nova Scotia Community Counts User Survey was disseminated to all 270 of its registered past and present users who have participated in Community Counts training since 2011, and does not include any anonymous users of the website, users who received training prior to 2011, or users who did not leave a valid email address. This pool was comprised of those Community Counts users that worked for various levels of government, community organizations, established private sector businesses, and active non-profits. In this way, the potential pool of respondents could 
differ greatly from the much larger general population of Nova Scotia, and those that accessed Community Counts anonymously, in that the respondent pool would be more likely to have skills and training in data use, or be required by their employment to interact with data on a regular basis. The survey was sent out by email three times over the course of October 2014 to January 2015 , in which users were asked to respond on a voluntary basis. Of the total sampling frame of 270 Community Counts users, 29 users responded (10.7\% response rate). Responses from the entire sample were tracked. The second and third round of responses served as reminders to those who were already contacted from the initial sample. After the third round, a final reminder was sent with the deadline for completion of January 30, 2015. In addition, during the key informant interviews, interviewees who did not fill out the survey were reminded to do so. Upon collection of all survey responses, qualitative and quantitative data coding was conducted to generate insight on trends between users of various sectors, types of work, type of projects conducted, types of datasets used, and other sources of statistical data used.

Subsequently, 16 key informants were selected from Community Counts users to participate in follow-up interviews. Some informants were selected from the Nova Scotia Community Counts User Survey who indicated willingness to participate in an interview. Others who did not complete the survey but worked closely with the Community Counts program in the past were contacted personally to ask to participate in the interview. All interviewees were located within the province of Nova Scotia, either employed in the public sector or for non-profit organizations. For example, one interviewee was employed as Geographic Information System (GIS) Officer for the Province of Nova Scotia's Department of Community Services. Another worked as a Public Health Officer for the Public Health Agency of Canada. Interviewees' work ranged from program planning in health, rural, housing, and social justice fields, to providing information to the public, research, mapping, and GIS. A full description of the type of work taken on by each of the interviewees can be found in Appendix I below. Analysis from these interviews provides greater depth and insight to the value of the program. The interview was semi-structured in nature, in which the same set of questions was posed towards all informants. The interview questions can be found in Appendix II below.

Due to the voluntary nature of the survey, responses will contain bias. These biases include convenience sampling bias, voluntary response bias and undercoverage, which should be noted throughout the analysis in this report. Bias may result from convenience sampling, as the survey was only sent out to the 270 Community Counts users who participated in Community Counts training in the past, not to anonymous users of the website. Community Counts training involved employees from the Nova Scotian provincial government traveling to various communities throughout the province, hosting workshops that introduced interested individuals to how to access, use, and interpret data and maps provided on the Community Counts website. Typical participants at these training sessions were government workers at various levels (town/city, regional, provincial), but also non-governmental organization and community workers, private sector workers, students, and citizens. Voluntary response bias may be present in the analysis, in which users with strong opinions on Community Counts may be overrepresented. Undercoverage may also be present, as the sample of respondents may not be proportionately representative of 
the population. For example, the sample of respondents contains a higher proportion of Provincial Government workers compared to the proportion of Provincial Government workers in the overall user population. Thus, insight from users in other sectors may be underreported. Within the key informant interviews, bias may be present due to convenience sampling. Interviewees who had a strong relationship with Community Counts were chosen within a larger subset of the program's users.

\section{Results}

\subsection{Survey Results: Description of the Community Counts User Base}

Of the 270 identifiable users have participated in Community Counts training workshops from 2011 onwards, 29 responded to the online survey. Users were classified by the following sectors: Provincial Government, Municipal Government, Business, Non-Profit, and Other. Of the 29 respondents to the Community Counts Survey, 19 (61\%) work for Provincial Government, 3 (10\%) for Municipal Government, 3 (10\%) for Business, 4 (13\%) for Non-Profit, and 2 (6\%) for Other as seen in Figure 2 below.

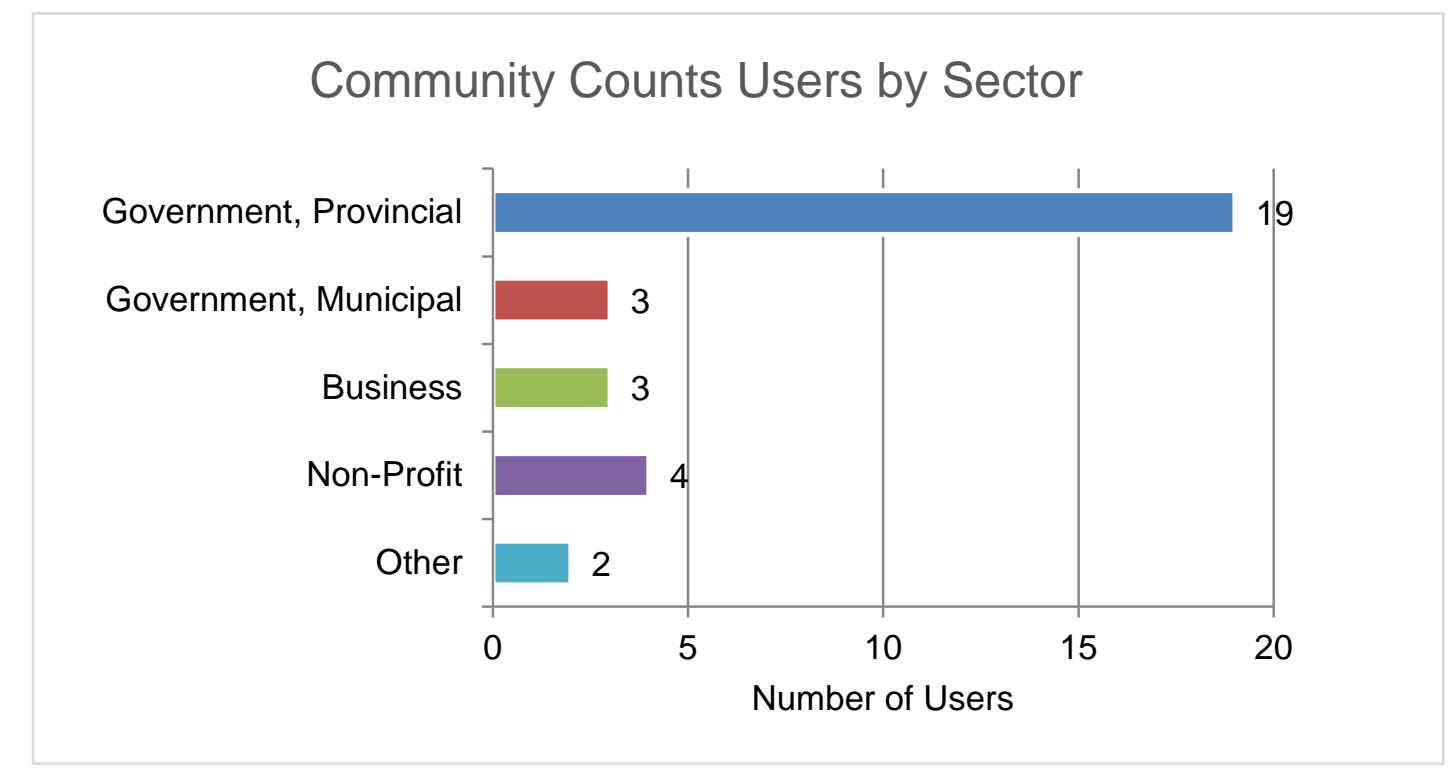

Figure 2: Community Counts Users by Sector, $n=29$

Users were then classified by the following types of work: Policy Analysis \& Development, Statistics, Land Use Planning \& GIS, Consulting, and Administration. Of the 29 respondents to the Community Counts Survey, 18 (62\%) work in Policy Analysis \& Development, 6 (21\%) in Statistics, $3(10 \%)$ in Land Use Planning \& GIS, 1 (3\%) in Consulting, and 1 (3\%) in Administration as seen in Figure 3 below. 


\section{Community Counts Users by Type of Work}

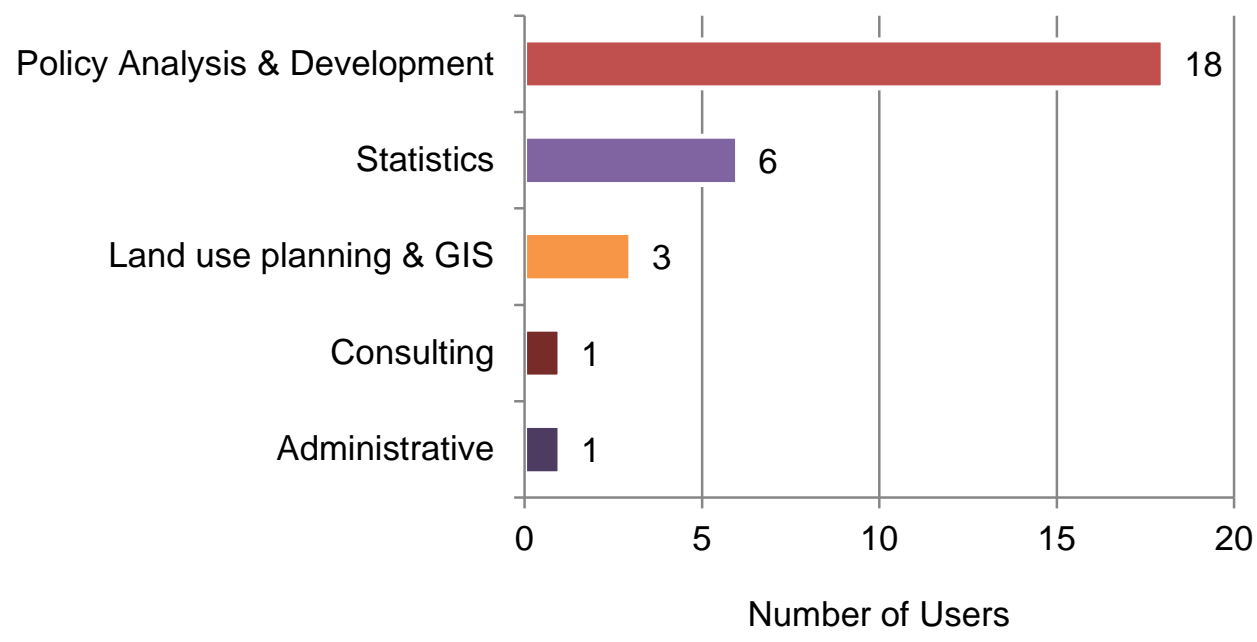

Figure 3: Community Counts Users by Type of Work, $n=29$

Next, an analysis of projects conducted using Community Counts was done to determine the data used within the website. Survey respondents collectively used Community Counts for a total of 32 projects. Projects were classified into types according to qualitative descriptions provided by survey respondents: Economic, Ethnic, First Nations, Health, Household, Political, Social, and Unspecified. Of the 32 projects recorded by survey respondents, $3(10 \%)$ were Economic, $3(10 \%)$ were Ethnic, 1 (3\%) was First Nations-based, 7 (22\%) were Health-based, 2 (6\%) were Householdbased, 1 (3\%) was Political, 7 (22\%) were Social, and 8 (25\%) were Unspecified as seen in Figure 4 below.

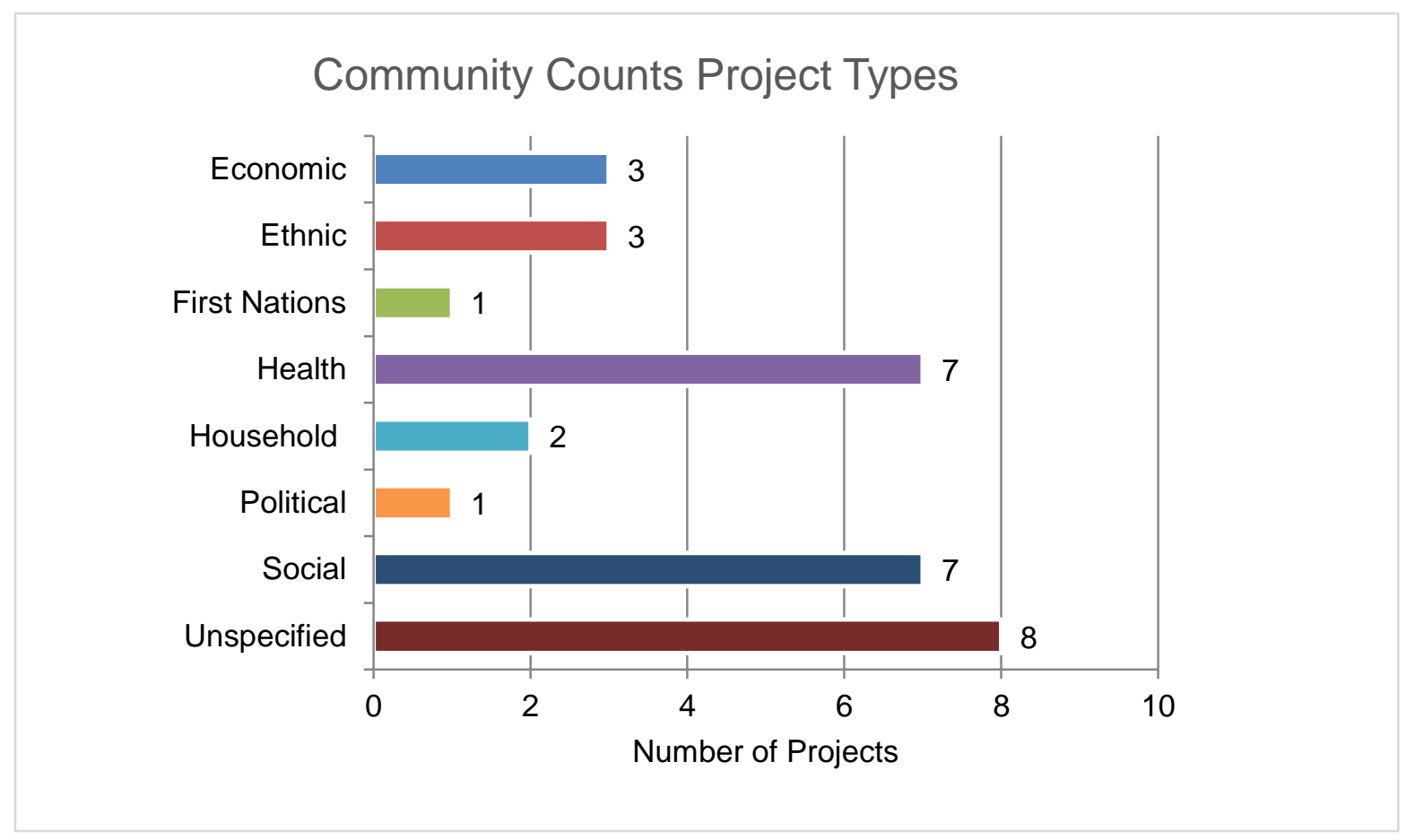


Figure 4: Community Counts Project Types, $n=32$

Economic projects recorded by respondents were related to job-creation, employment and investment. Ethnic projects were related to programs for specific cultural or racial groups, such as African Nova Scotians, and tailoring to ethnic demographics in general. Health projects were related to childcare health screening, primary health care, disease, municipal physical activity programs, pharmacare, and infant health. Political projects were related to electoral district planning. Social projects included projects on community planning, rural area planning, youth development and sexual violence prevention. First Nations projects were related to planning specifically for First Nations ancestry-identified individuals. Household projects were related to housing needs and indexes on housing. Unspecified projects recorded by respondents lacked specific details.

An analysis of the types of datasets used in Community Counts was done to provide another perspective on data used within the website. Datasets were classified into subject type: Demographics, Education, Environment, Health, Households, Income, Labour, Production, Resources, Social and Unspecified. Examples of Demographics datasets include Population by Selected Age Groups, Migration Estimates by Gender and Age Group, Visible Minorities by Age and Gender, among others. Examples of Production datasets include Aquaculture Employment by Species of Fish, Business Location Counts, amongst others. Of the 76 datasets used by survey respondents, 26 (24\%) were from Demographics, 7 (9\%) were from Education, 1 (1\%) was from Environment, $6(8 \%)$ were from Health, $3(4 \%)$ were from Households, 9 (12\%) were from Income, 4 (5\%) were from Labour, 2 (3\%) were from Production, 1 (1\%) was from Resources, $5(7 \%)$ were from Social, and 12 (16\%) were Unspecified as seen in Figure 5 below.

\section{Type of Dataset Used}

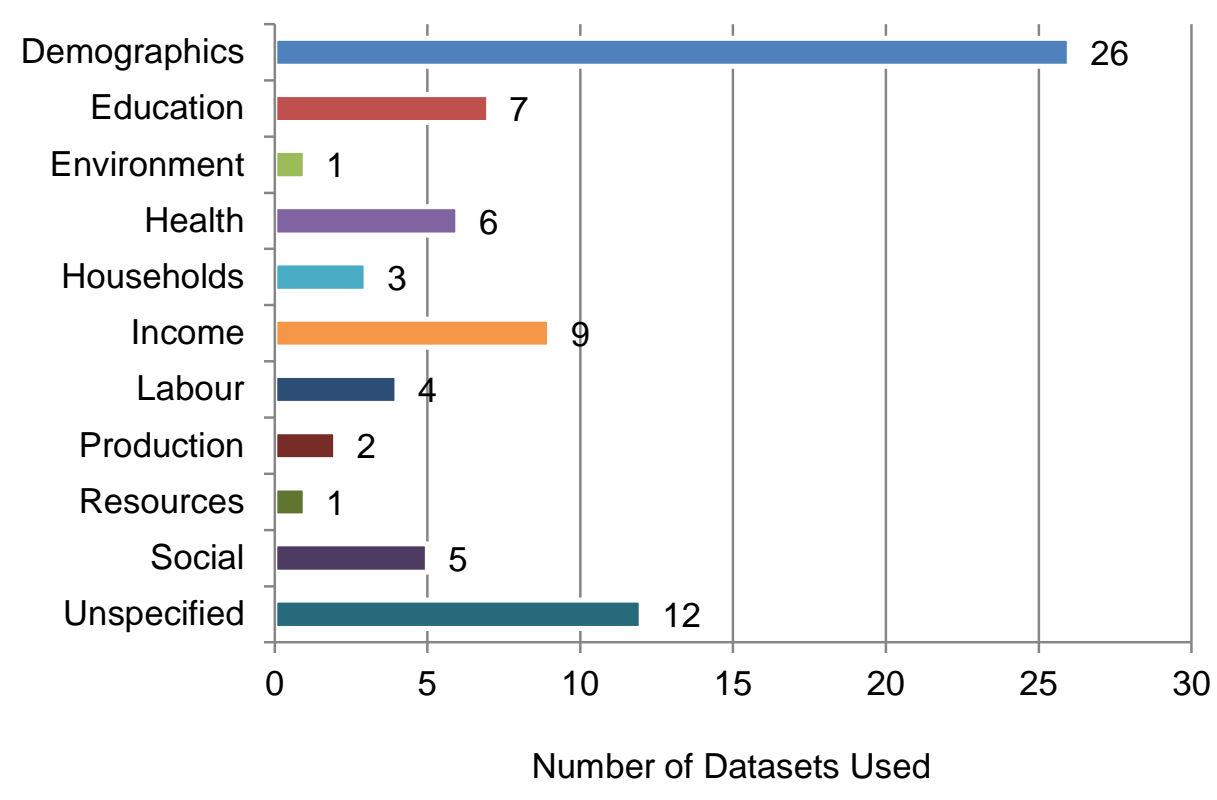


Figure 5: Type of Dataset Used, $n=76$

\subsection{Interview Results}

An analysis of the interviews was then conducted to determine the overall uses, benefits, impacts, and value derived by Community Counts users. Key Informants were asked how they use Community Counts in their work. Uses of Community Counts were classified into categories ranging from asset mapping, cross-referencing, communicating information, gathering information, providing services, community engagement, determine economic value of assets, graphics, contribute data to the Community Counts program, determine economic value of assets, decision-making, refer other users to statistical data, and land use planning.

Table 1: Uses of Community Counts

\begin{tabular}{|l|l|}
\hline Uses & $\begin{array}{l}\text { Percent of } \\
\text { Responses* }\end{array}$ \\
\hline Asset Mapping & $17 \%$ \\
\hline Communicating Information & $13 \%$ \\
\hline Cross Referencing & $13 \%$ \\
\hline Gathering Information & $13 \%$ \\
\hline Providing Services & $10 \%$ \\
\hline Community Engagement & $7 \%$ \\
\hline Graphics & $7 \%$ \\
\hline $\begin{array}{l}\text { Contribute data to Community Counts } \\
\text { program }\end{array}$ & $7 \%$ \\
\hline Determine Economic Value of Assets & $3 \%$ \\
\hline Decision-making & $3 \%$ \\
\hline Refer Users to Data & $3 \%$ \\
\hline Land Use Planning & $3 \%$ \\
\hline
\end{tabular}

*Total number of responses, $\mathrm{n}=16$

Table 1 above shows the range of tasks conducted by informants using Community Counts. The program is most frequently used by informants for asset mapping, communicating information, cross-referencing, and gathering information.

Next, key informants were asked to specify the benefits and impacts resulting from their use of Community Counts. Intended benefits of the program were to provide easy access to social and economic data, allowing communities to map a big picture of themselves and compare it with other communities. In particular, the program aimed to support evidence-based decisions by 
governments and organizations, particularly related to the health and well-being of Nova Scotians and to developing sustainable communities. Intended versus actual benefits of the program can be observed in the interviewees' responses. After all interviews were conducted, the responses were classified into categories which included: Economic, Social, and Technical, and further broken down into subcategories as seen in Table 2 below.

Table 2: Benefits, Impacts and Value derived from Community Counts

\begin{tabular}{|c|c|}
\hline Type of Benefit & $\begin{array}{l}\text { Percent of } \\
\text { Responses* }\end{array}$ \\
\hline \multicolumn{2}{|l|}{ Economic } \\
\hline Time Saved & $24 \%$ \\
\hline Money Saved & $6 \%$ \\
\hline Mapping Service & $6 \%$ \\
\hline Graphics for Presentations & $4 \%$ \\
\hline \multicolumn{2}{|l|}{ Social } \\
\hline Local-level Information & $20 \%$ \\
\hline Improved Data Literacy & $8 \%$ \\
\hline Population Data & $6 \%$ \\
\hline Proof of Evidence & $6 \%$ \\
\hline Socio-Economic Factors & $2 \%$ \\
\hline \multicolumn{2}{|l|}{ Technical } \\
\hline Central Source of Data & $10 \%$ \\
\hline Reliable Source of Data & $6 \%$ \\
\hline Accessible Source of Data & $1 \%$ \\
\hline
\end{tabular}

*Total number of responses, $\mathrm{n}=16$

Table 2 shows the range of benefits stated by informants. Community Counts' provision of the Map Centre is classified as an economic benefit as it saves users from paying for other data sources and services that require a fee. Local-level information is a social benefit as it helps with policymaking or planning decisions. Improved data literacy is a social benefit as it results in more productive policy discussion around the data. Population data is also a social benefit as data on targeted groups provides useful information on certain demographics. The most frequently stated benefit of Community Counts is time saved. The second most frequently stated benefit of the program is providing local-level information that cannot be found elsewhere. In addition, informants were asked to quantify the benefits of Community Counts. Limited responses were given on the concrete numerical value of Community Counts. Table 3 below captures the 
responses of the few users who were able to provide a quantitative value to their use of the program in terms of time saved.

Table 3: Time Saved Using Community Counts

\begin{tabular}{|l|l|}
\hline Duration & $\begin{array}{l}\text { *Percent of } \\
\text { Responses }\end{array}$ \\
\hline Up to a full day & $20 \%$ \\
\hline Half the time & $20 \%$ \\
\hline Unspecified & $60 \%$ \\
\hline
\end{tabular}

*Total number of responses, $\mathrm{n}=10$

Of the ten users who indicated "time saved" as a benefit of using Community Counts, two users stated that Community Counts saved up to eight hours of work on research, and two users stated that the program was able to reduce work time in half. Six users did not specify numerically the amount of time saved with the program. No users were able to specify the amount of monetary benefits derived through using Community Counts, though saving staff time would likely have an impact on improving productivity. Thus, an analysis could not be provided on the monetary value of using Community Counts.

\subsection{Sector Study Summaries}

Sector studies were drafted from nine of the key informants to provide greater depth in responses. Table 4 below shows a summary of the Community Counts interviews. Key informants were selected based on a diverse range of work, including map-making, program planning, capacity building, policy development, research, and public engagement. These sector studies also expand upon informants' uses of Community Counts, in which asset mapping, gathering information, community engagement and communicating information were main uses. These sector studies illustrate specific examples of the main benefits derived from Community Counts as seen in the table below. Time saved was a benefit of the program as many users were able to use available data rather than compile data from scratch. One user saved time by directing stakeholder inquiries on statistical data to Community Counts, compared to spending their own time answering the request. Local-level information was a benefit as users were able to compare resources available in one community versus another, or compare information from one's own jurisdiction with others across the province. Furthermore, the sector studies provide insight on the types of stakeholders who benefit from Community Counts. Responses ranged from internal stakeholders such as senior managers, program planners and other staff, as well as external stakeholders such as individuals on community committees, and targeted audiences for which the respective programs are meant to serve. 
JeDEM 8(1): 1-27, 2016

ISSN 2075-9517

http://www.jedem.org

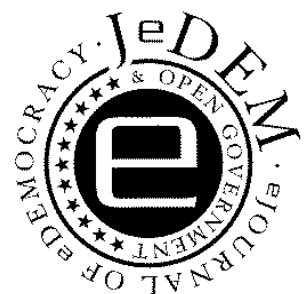

Table 4: Community Counts Sector Study Summaries from Key Informant Interviews

\begin{tabular}{|c|c|c|c|c|c|}
\hline & Role & Job Description & Uses of Community Counts & Benefits of Community Counts & Who benefits \\
\hline 1. & $\begin{array}{l}\text { GIS OFFICER, } \\
\text { DEPARTMENT OF } \\
\text { COMMUNITY } \\
\text { SERVICES, } \\
\text { PROVINCIAL } \\
\text { GOVERNMENT }\end{array}$ & $\begin{array}{l}\text { Makes maps to help } \\
\text { policy-makers decide } \\
\text { where to allocate } \\
\text { funding (e.g., to } \\
\text { minority groups, for } \\
\text { social assistance, etc.) }\end{array}$ & $\begin{array}{l}\text { ASSET MAPPING (e.g., to build } \\
\text { new office boundaries matching } \\
\text { existing Community Counts } \\
\text { boundaries for the purpose of } \\
\text { extracting reliable statistics), } \\
\text { GATHER INFORMATION (e.g., on } \\
\text { department assets to discover } \\
\text { their proximity to specific } \\
\text { geographic boundaries) }\end{array}$ & $\begin{array}{l}\text { TARGETED POPULATION DATA, LOCAL- } \\
\text { LEVEL INFORMATION, BETTER- } \\
\text { INFORMED DECISION-MAKING, } \\
\text { ACCESSIBLE SOURCE OF DATA }\end{array}$ & $\begin{array}{l}\text { SENIOR } \\
\text { MANAGEMENT, } \\
\text { PROGRAMMERS } \\
\text { AND PROGRAM } \\
\text { STAFF, THE } \\
\text { GENERAL PUBLIC }\end{array}$ \\
\hline 2. & $\begin{array}{l}\text { HEALTH } \\
\text { ECONOMIST, } \\
\text { DEPARTMENT OF } \\
\text { HEALTH AND } \\
\text { WELLNESS, } \\
\text { PROVINCIAL } \\
\text { GOVERNMENT }\end{array}$ & $\begin{array}{l}\text { Forecasts and } \\
\text { predicts costs for } \\
\text { various healthcare } \\
\text { programs. }\end{array}$ & $\begin{array}{l}\text { GATHER INFORMATION (e.g., } \\
\text { demographic statistics on health } \\
\text { jurisdictions) }\end{array}$ & $\begin{array}{l}\text { TIME SAVED, RELIABLE SOURCE OF } \\
\text { DATA, LOCAL-LEVEL INFORMATION, } \\
\text { GRAPHICS, ACCESSIBLE SOURCE OF } \\
\text { DATA }\end{array}$ & $\begin{array}{l}\text { DECISION-MAKERS } \\
\text { IN THE } \\
\text { DEPARTMENT }\end{array}$ \\
\hline 3. & $\begin{array}{l}\text { PROGRAM } \\
\text { COORDINATOR, } \\
\text { DEPARTMENT OF } \\
\text { COMMUNITY } \\
\text { SERVICES, } \\
\text { PROVINCIAL } \\
\text { GOVERNMENT }\end{array}$ & $\begin{array}{l}\text { Outreach work to } \\
\text { support and build } \\
\text { capacity of the non- } \\
\text { profit sector. }\end{array}$ & $\begin{array}{l}\text { ASSET MAPPING (e.g., justice } \\
\text { centers, resources for youth, } \\
\text { churches, etc.) }\end{array}$ & $\begin{array}{l}\text { LOCAL-LEVEL INFORMATION, PROOF } \\
\text { OF EVIDENCE (i.e. for non-profit } \\
\text { groups who use the data in } \\
\text { proposals written to government) }\end{array}$ & $\begin{array}{l}\text { NON-PROFIT } \\
\text { GROUPS } \\
\text { SUPPORTED BY } \\
\text { GOVERNMENT } \\
\text { DEPARTMENTS }\end{array}$ \\
\hline
\end{tabular}




\begin{tabular}{|c|c|c|c|c|c|}
\hline 4. & $\begin{array}{l}\text { EPIDEMIOLOGIST, } \\
\text { FEDERAL PUBLIC } \\
\text { HEALTH AGENCY }\end{array}$ & $\begin{array}{l}\text { Develop community } \\
\text { health profiles and } \\
\text { support programs of } \\
\text { health district } \\
\text { authorities. }\end{array}$ & $\begin{array}{l}\text { GATHER INFORMATION (e.g., } \\
\text { access statistics to support the } \\
\text { development of community } \\
\text { snapshots), COMMUNICATING } \\
\text { INFORMATION (e.g., fulfill } \\
\text { information requests from } \\
\text { stakeholders) }\end{array}$ & $\begin{array}{l}\text { TIME SAVED, CENTRAL SOURCE OF } \\
\text { DATA, VISUAL OF MULTIPLE SOCIO- } \\
\text { ECONOMIC FACTORS (i.e. for better } \\
\text { context of causal factors to health for } \\
\text { policy-making), POPULATION DATA } \\
\text { (useful to apply population rather } \\
\text { than individual approach in public } \\
\text { health) }\end{array}$ & $\begin{array}{l}\text { BUSINESS } \\
\text { PLANNERS, } \\
\text { COMMUNITY } \\
\text { HEALTH BOARDS, } \\
\text { DISTRICT HEALTH } \\
\text { AUTHORITY } \\
\text { QUALITY TEAMS, } \\
\text { DIRECTOR OF } \\
\text { PUBLIC HEALTH, } \\
\text { MINISTRY OF } \\
\text { HEALTH SENIOR } \\
\text { MANAGEMENT, } \\
\text { AND RESEARCHERS }\end{array}$ \\
\hline 5. & $\begin{array}{l}\text { MUNICIPAL } \\
\text { PLANNER, } \\
\text { MUNICIPAL } \\
\text { GOVERNMENT }\end{array}$ & $\begin{array}{l}\text { Public Relations for } \\
\text { Land Use Bylaw, } \\
\text { meet with } \\
\text { community groups to } \\
\text { communicate } \\
\text { legislative impacts. }\end{array}$ & $\begin{array}{l}\text { Refer external users to statistical } \\
\text { data, land use planning (e.g., } \\
\text { predict success or failure of } \\
\text { proposed land use plans), gather } \\
\text { information (e.g., municipal } \\
\text { population growth research) }\end{array}$ & $\begin{array}{l}\text { TIME SAVED (e.g., can direct local } \\
\text { inquires to Community Counts } \\
\text { instead of creating the data from } \\
\text { scratch), LOCAL LEVEL INFORMATION } \\
\text { (e.g., can compare own municipality } \\
\text { with others across the province) }\end{array}$ & $\begin{array}{l}\text { STAFF WITHIN THE } \\
\text { MUNICIPALITY, } \\
\text { POLITICIANS } \\
\text { WITHIN THE } \\
\text { COMMUNITY, AND } \\
\text { THE GENERAL } \\
\text { PUBLIC }\end{array}$ \\
\hline 6. & $\begin{array}{l}\text { PROGRAM } \\
\text { COORDINATOR, } \\
\text { COMMUNITY JUSTICE } \\
\text { ORGANIZATION }\end{array}$ & $\begin{array}{l}\text { Address youth gun } \\
\text { violence through } \\
\text { community } \\
\text { mobilization and } \\
\text { education. }\end{array}$ & $\begin{array}{l}\text { ASSET MAPPING (e.g., to map } \\
\text { incidents of violence and } \\
\text { determine resource gaps to meet } \\
\text { needs of clients) }\end{array}$ & $\begin{array}{l}\text { PROVIDING MAPPING SERVICES, } \\
\text { LOCAL-LEVEL INFORMATION (e.g., to } \\
\text { compare resources available in one } \\
\text { community versus another) }\end{array}$ & $\begin{array}{l}\text { CLIENTS, STAFF, } \\
\text { COMMITTEE } \\
\text { MEMBERS WHO } \\
\text { PROVIDE INSIGHT } \\
\text { ON VIOLENCE } \\
\text { WITHIN THE LOCAL } \\
\text { AREA } \\
\end{array}$ \\
\hline 7. & $\begin{array}{l}\text { RESEARCH \& } \\
\text { STATISTICS OFFICER, } \\
\text { DEPARTMENT OF } \\
\text { COMMUNITIES, } \\
\text { CULTURE \& }\end{array}$ & $\begin{array}{l}\text { Determine GDP value } \\
\text { of culture in the } \\
\text { province, research the } \\
\text { importance of culture } \\
\text { to citizens. }\end{array}$ & $\begin{array}{l}\text { DETERMINE THE ECONOMIC } \\
\text { VALUE OF ASSETS (i.e. research } \\
\text { GDP figures for culture based } \\
\text { on Community Counts Map } \\
\text { Centre feature and other }\end{array}$ & $\begin{array}{l}\text { PROVIDING MAPPING SERVICES, TIME } \\
\text { SAVED (i.e. no longer required to } \\
\text { physically look up individual } \\
\text { cultural assets in the province) }\end{array}$ & $\begin{array}{l}\text { DEPARTMENT } \\
\text { MEMBERS, } \\
\text { RESEARCH AND } \\
\text { GOVERNMENT } \\
\text { RELATIONS }\end{array}$ \\
\hline
\end{tabular}




\begin{tabular}{|l|l|l|l|l|l|}
\hline & $\begin{array}{l}\text { HERITAGE, } \\
\text { PROVINCIAL } \\
\text { GOVERNMENT }\end{array}$ & sources) & & \\
\hline 8. & $\begin{array}{l}\text { POLICY } \\
\text { CONSULTANT, } \\
\text { REPORT ON } \\
\text { PROVINCIAL } \\
\text { ECONOMIC } \\
\text { DEVELOPMENT }\end{array}$ & $\begin{array}{l}\text { Writing and research } \\
\text { for a report on the } \\
\text { province's state of } \\
\text { economic well-being. }\end{array}$ & $\begin{array}{l}\text { COMMUNICATING INFORMATION } \\
\text { (e.g., used Community Counts' } \\
\text { data as proof of evidence for the } \\
\text { report), COMMUNITY } \\
\text { ENGAGEMENT (e.g., used } \\
\text { Community Profiles to obtain } \\
\text { local context of communities for } \\
\text { hosting public engagement } \\
\text { sessions) }\end{array}$ & $\begin{array}{l}\text { PROOF OF EVIDENCE (e.g., provides } \\
\text { factual support for policy } \\
\text { recommendations), DATA LITERACY, } \\
\text { TIME SAVED (i.e. cuts down research } \\
\text { time in half) }\end{array}$ & $\begin{array}{l}\text { LOCAL } \\
\text { COMMUNITY } \\
\text { MEMBERS }\end{array}$ \\
\hline 9. & $\begin{array}{l}\text { HEALTH PLANNER, } \\
\text { DISTRICT HEALTH } \\
\text { AUTHORITY }\end{array}$ & $\begin{array}{l}\text { Plan and evaluate } \\
\text { health services for } \\
\text { primary care. }\end{array}$ & $\begin{array}{l}\text { PROVIDING SERVICES (i.e. health } \\
\text { care services appropriate for the } \\
\text { demographic), COMMUNITY } \\
\text { ENGAGEMENT (i.e. to show } \\
\text { stakeholders the demographic } \\
\text { context for decision-making), } \\
\text { GRAPHICS }\end{array}$ & $\begin{array}{l}\text { TIME SAVED (e.g., eliminates need to } \\
\text { create own geographic boundaries), } \\
\text { RELIABLE SOURCE OF DATA, PROOF OF } \\
\text { EVIDENCE (e.g., provide support } \\
\text { when community members inquire } \\
\text { about the district's decisions) }\end{array}$ & $\begin{array}{l}\text { HEALTH BOARDS } \\
\text { AND VOLUNTEER } \\
\text { HEALTH } \\
\text { COMMITTEES WHO } \\
\text { REPRESENT THE } \\
\text { COMMUNITIES }\end{array}$ \\
\end{tabular}


JeDEM 8(1): 1-27, 2016

ISSN 2075-9517

http://www.jedem.org

\section{Discussion}

\subsection{Government Support of Open Data Delivery and Use}

While it is not necessary for open data provision to be a component of a broader open government policy, Francoli (2011) discusses the importance of open governance for open data delivery. Governments should look towards not only releasing information but also meeting goals of openness, sharing, collaboration, and transparency. A critical component of this is ensuring that data released is appropriate for a specific audience of users. This contrasts the potential for open data to serve as a "digital distraction" from open government ( $Y u$ \& Robinson, 2012; Johnson \& Robinson, 2014), with the release of superfluous, or low-value data at the expense of high-value data in demand by users. Drawing from lessons learned in the Community Counts experience, we consider key ways in which government can support the actual use of open data, as opposed to simple data provision. This represents a maturation of the open data provision model, where governments take a more activist stance (Sieber \& Johnson, 2015). Specific actions taken by Community Counts include; initiating community engagement on open data use, awareness of open data across the organization, and building the platform using a collaborative approach.

\subsubsection{Community Engagement}

Evidence from Currie (2013), and Sieber \& Johnson (2015) demonstrate that strong community engagement between government and citizens contributes to data use empowerment. Data use empowerment is evident when citizens utilize the data from the open data platform, and then want to contribute to improving a component of the data provisioning system, for example, by suggesting corrections to data or requesting new datasets (Davies, 2010; Currie, 2013; Johnson, 2016). Community engagement is important to open data use, as citizens bring local-level knowledge and insight into grassroots data usage to government open data programs. Engagement from government to citizens can take the form of both online and offline outreach (Howard, 2012). A common form of online engagement is utilizing social media, such as Twitter or blogs, to allow citizens to ask questions, request data, and discuss improvements to the open data platform. A common form of offline engagement is involving the local community in developing the interface and tools for an open data program in events such as hackathons and app contests (Davies \& Edwards, 2012; Currie, 2013; Johnson \& Robinson, 2014). While Community Counts did not directly engage citizens in these types of activities to enhance the open data provisioning system, it did demonstrate community engagement by acting as an infomediary, taking raw data and producing more accessible community statistical profiles and output, such as maps. Opening 
data has many challenges for both data providers and data users (Magalhaes et al., 2013), especially as massive amounts of data are released at once, with varying levels of quality control and completeness (Sieber and Johnson, 2015). The quantity and inconsistency of data release, along with other technical barriers of data formatting, can limit the common citizen from making valuable use of the data. Thus information intermediaries - or "infomediaries" - are useful in coordinating the exchange of data between data providers and users and in establishing an effective open data system (Magalhaes et al., 2013; Janssen \& Zuiderwijk 2014).

\subsubsection{Cross-Organizational Support}

Evidence from Currie (2013), Nam \& Pardo (2014), and Janssen \& Zuiderwijk (2014) demonstrate that cross-organizational support contributes to greater availability and accessibility of data for users. Cross-organizational support occurs when employees in multiple departments supply a diverse range of data to a single organizational open data platform. To foster cross-organizational support, employees across departments should be aware of the importance of open data and its application within their particular mandate as well as the potential to reach out to citizens. Education would enable representatives from each department to understand how to contribute data produced by their department and develop a policy to address open data requests from citizens. This case study of Nova Scotia Community Counts provides evidence on the impact of cross-organizational support towards enabling an open data program. Support and initiative for Community Counts came from various departments across the province of Nova Scotia, including the Departments of Health and Justice, who were the first cross-organizational bodies that requested the use of Community Counts for the publicizing of data and contributed financial resources to do so (M. Shookner, personal communication, January 19, 2015). The ability of these agencies to develop internal mechanisms to contribute departmental data played a key role in the success of Community Counts, and supported its ability to provide data for a diverse range of users. Feedback from these departments provided insight on additional data that users preferred to see on the website.

Cross-departmental support could help raise awareness of open data within the government, build capacity so that it meets the technical needs of the external community, and help users understand the value of open data. Furthermore, in Nam \& Pardo's research (2014) on Philadelphia's Philly311 system, a citywide initiative that involves the compilation of nonemergency data onto a single platform, cross-organizational support was utilized to write servicelevel agreements. The service level agreements are contracts to determine the deadlines and quality of data expected to be delivered by staff to external clients. By drafting the agreements in a cross-organizational fashion, individuals from different departments were able to gain awareness of the roles of other departments. This fostered better customer service provision as individuals from all departments could respond more efficiently to information requests or direct information requests appropriately and ultimately contributed to better management of the initiative. These case studies illustrate the importance of cross-department collaboration and demonstrate that it plays a role to support open data use. 


\subsubsection{Collaborative Culture}

Community Counts maintained an approach of utilizing collaborative efforts to improve the program. While other open data initiatives have benefited from private-sector partnerships, technical, and financial support, Community Counts maintained an informal network of support across various departments and with Community Counts users. By maintaining friendly connections with users, offering free training, providing personal assistance for users who run into problems, and obtaining continual feedback from users, Community Counts delivered high quality service to its users. This was a main contributing factor in how Community Counts not only released statistical data but also empowered users to incorporate data into their work. Overall, these three attributes of community engagement, cross-organizational awareness, and a collaborative culture can help open data programs empower more data users to understand and value open data programs beyond simply delivering data (Bartenberger \& Grubmüller, 2014).

\subsection{Infomediary Role of Community Counts}

Although much has been done to release datasets and to create technological applications to use data, members of the general public, specifically from the non-technical community, are generally unaware of open data (Currie, 2013; Roberts, 2012; Roy, 2014; Wadud, 2014). Data literacy, which is the understanding of how to access and use open data to create information, has not kept up with the rate of data release. This undermines the social benefit of allowing the public to access and reuse data, possibly restricting the continued expansion of open data programs, as broad-based value may not be easily identified. As Roy (2014) mentions, open data will not be adopted unless the public at large understands its value.

A recurring theme throughout the analysis of Community Counts' uses and benefits is that the program assisted individuals in finding and using data in a meaningful way. Thus, Community Counts played a role in promoting data literacy, acting as an infomediary by gathering government information and presenting it in a way that is usable and comprehensible to others. The release of data in its raw form is often opaque to the non-expert, acting as a barrier to data use. Magalhaes et al. (2013) state that information systems should be modelled on interdependent "ecosystems", which not only include providers and users of data, but also innovators who provide services for data interpretation. As presented by Janssen \& Zuiderwijk (2014), infomediaries generate added value to information-intensive business models for both the providers of data and the users of data, benefiting citizens, businesses, and public bodies (Magalhaes et al., 2013). They do so by aggregating information, matching supply and demand of data, and being trusted agents (Janssen \& Zuiderwijk, 2014). Janssen \& Zuiderwijk (2014) also mention the role of infomediaries in several more specific ways, including ensuring ease of visualizing information, promoting the ability for users to add content, aggregating information from multiple sources, providing comparisons of various assets, and searching and processing information.

Community Counts has played an infomediary role, taking raw data and transforming it into information, and supporting a community of users. This role has been realized by 1) providing 
data tailored to the local community, 2) by allowing users to compare data between jurisdictions, 3) by helping non-statistical users engage in discussion over the data, 4) by serving as a central, reliable, and accessible source of data, and 5) by working collaboratively with stakeholders to meet new data requests. By providing data tailored to the local community, users across sectors from the provincial health care sector, municipal planning, and policy development, have found the program equally useful or more useful than sources that only provide national or provincial-level data. Users were able to gain a local context of the community and find a variety of specific information on health, education, income, and others tailored to local communities. Second, by enabling access to data not only on one local jurisdiction but to all jurisdictions across the province on 16 geographic levels, users could compare data from jurisdiction to jurisdiction in a standardized way. This provides consistency and better data comprehensibility, compared to aggregating data from multiple sources, in which errors may occur. Third, Community Counts presented data in a variety of formats, which helped non-technical users engage with data. With tables, maps, charts, and policy-specific visuals, users with non-technical backgrounds could interpret the data and adapt the information for their own use. Key informant interviewees mentioned that community members engaged with governments, who would often discuss an issue based on emotion with a bias from their own industry perspective, could use Community Counts to approach discussions with a more objective and fact-based point of view. Fourth, by serving as a central, reliable, and easily accessible source of statistical data, Community Counts helped users save time and money, thus incentivizing data use with economic benefits. Finally, the Community Counts' administrative team maintained a connection with users, offers free training, providing personal assistance for users to access data and responded to inquiries about data availability. By meeting individual requests and educating a range of users from various sectors and industries to use data, the Community Counts program promoted data use for a wide range of individuals and organizations, beyond those technically adept enough to access raw open data directly.

While data literacy is a recurring issue in the open data world, Community Counts presented a successful case for engaging the wider community, serving as a catalyst to improve data literacy. The analysis summarized in this paper demonstrates the additional value and benefit derived when users are engaged in utilizing public information sources. By serving as a central and reliable source of statistical data, providing data tailored to the local demographic, allowing users to compare data between jurisdictions, and formatting data in a way that allows non-statistical users to engage in discussion over the data, these benefits have translated to savings in time and money. This study reveals the importance of harnessing the social benefits of open data, as it provides additional incentive for users to engage in data, thereby increasing open data usage and allowing further value to be realized by a more diverse base of users.

\section{Conclusion}

This research aims to assess the role open data infomediaries play in enabling open data use, recognition of its full economic value, and provide a summary of the outcomes of the Community 
Counts program. Given the recent closure of the Community Counts program, it is an appropriate time to reflect on the lessons that can be learned from a decade of providing open data, and what signals the success of Community Counts can send to other government open data programs.

The Nova Scotia Community Counts program was successful in fostering a collaborative culture with users and building capacity through cross-organizational support and providing free statistics training. Many government open data programs focus on the release of datasets and engagement of technical data users who can make use of raw data, compared to in-house processing, analysis, and interpretation of data. By only engaging a technical audience, a large fraction of potential users - consisting of the members of the non-technical community - can be overlooked. A collaborative culture in which feedback is continually obtained to determine user needs is critical to engaging a wide array of individuals from the non-technical community. Conducting a user survey and interviews for this study has demonstrated the benefit of outreach and obtaining feedback. As illustrated by the responses in the interviews, the main benefits of the Community Counts program were time saved, provision of local-level information, a central source of data, improved data literacy, provision of targeted population data, and proof of evidence to support decision-making. These responses show what users are looking for and how to better meet a wide array of diverse user needs. Furthermore, through the in-person interviews, users were able to provide valuable constructive feedback on improvements to the types of data and formatting that could be made to the website.

The approach used in this study, a user survey and key informant interviews, provided insight on the qualitative benefits of open data within a specific regional context. This stands in contrast to open data valuation studies, such as the approach of the Open Data 500 (The GovLab, 2016a), to match data provided by governments around the world with specific sectors and industries. This matching approach provides a high-level view of how open data is being shared, but ignores many of the contextual factors that drive specific cases where open data has been employed to good effect. These qualitative benefits are economic, social, and technical in nature, and include the diverse ways in which individuals use open data, from program planning to addressing information requests. Evaluating benefits in a qualitative manner is a key method of analyzing the value of open data and may be best captured through descriptive reports, such as through the sectoral case studies as illustrated above in Table 4. Qualitative benefits should be assessed according to indicators and categories established by international open data standards in order to ensure all types of benefits are captured appropriately. For example, the benefits of Community Counts are grouped similar to the categories listed by the Open Data Barometer (2015), including economic, social, and technical categories, which follow the economic impact category (including economic growth, government efficiency) and social impact category (transparency and accountability, inclusion of marginalized groups). Similarly, recent studies by The GovLab (2016b) to build a library of case studies of open data impact from around the world supports our approach to valuing open data from a local implementation perspective.

Limitations of this study include that convenience sampling was present, in which interviewees were selected based on those who used Community Counts data frequently. Furthermore, only a small sample of total Community Counts users responded to the survey. Undercoverage may also 
be present, as the sample of respondents contains a higher proportion of Provincial Government workers compared to the proportion of Provincial Government workers in the overall user population. The scope of current research on open data use is also generally limited to qualitative case studies or high-level surveys. More research must be done to understand the quantitative benefits to open data, such as time and money that has been saved through a specific instance of an open data program. Capturing these values would require a more detailed analysis, for example, by comparing the production time of work with and without open data for individual open data users. A baseline measure of the economic value of open data can then also be captured through multiplying the open data user's hourly salary (or reasonable estimate if volunteer labour) with the number of hours of time saved. Other means of analyzing quantitative benefits include the number and range of applications developed using open data and the usage rate of these technical applications by the public or other data users. Furthermore, these benefits can be measured by tracking the number of individuals who use the open data platform, data downloads, number of users who attend public engagement events, and benchmarking progress from year-toyear.

Overall, the open data movement can benefit from the lessons learned evaluating the Community Counts case study. Significantly, Community Counts acted as a data infomediary, that is an entity that takes raw government open data (in this instance largely from federal and provincial sources) and adds additional value for users who are not technically savvy enough to tap into the sources of raw data. These users cover a broad range, from professionals working for government (such as the survey sample) to the broader citizenry. While the non-technical audience is often overlooked in favour of a technical audience use of open data, the use of an infomediary program, such as Community Counts, to engage and tailor resources to a non-technical audience can increase open data usage and allow further value to be realized in the open data sphere. The closure of Community Counts, despite notable areas of benefit for the user community, speaks to a lack of recognition on the part of government of the value of open data, and the difficulty that open data advocates may have with pointing to specific instances of value or program success. The lack of easily identifiable indicators of open data value means that more potentially timeconsuming methods, such as those presented in this research, are required to assess the value of a specific program, and communicate this value to open data stakeholders. For other public agencies currently delivering open data, we recommend a serious look at developing rigorous assessment metrics and establishing a strong rapport with open data decision-makers to make program decisions based on evidence of value generated through open data provision.

\section{Appendix I - Interviewee's Type of Work}

Program Planning: 
- Plan and evaluate Health services

- Policy consulting, plan and evaluate Rural and Coastal services

- Plan and evaluate programs, requests, and business plans related to Housing services

- Plan and evaluate Social services for violence prevention

- Plan and Evaluate Justice programs

Provide Information to the Public:

- Provide information to external parties as requested

- Address data requests from Justice Enterprise Information Network

- Annually release provincial and territorial data and perform the analytics for economic value of culture

- Fulfill information requests from staff in public health and the broader health system

Capacity Support:

- $\quad$ Provide support for policy advisors

- Support the Non-Profit sector

Research:

- Determine GDP value of culture, research on the importance of culture to Nova Scotians

Geographic Information Systems:

- Make maps for Community Services

- GIS \& Data Analysis, custodian of data

\section{Appendix II - Semi-Structured Interview Questions}

Empirical Survey of Open Data Users ...or... Who uses Community Counts and for what? 


\section{Key Informant Interview}

January 26, 2015

Thank you for agreeing to participate in this follow-up interview to the Community Counts Users Survey. The purpose of this interview is to learn more about how you use Community Counts and the benefits that you derive from using it. We plan to develop several case studies from these interviews that would be used to inform future development of data and features, as well as informing senior policy makers about the benefits Community Counts provides to Nova Scotians as a public information resource.

1. Name of key informant

2. Organization

3. What sector do you work in? (Could be paid or volunteer work)

a. Academic

b. Business _ Sector

c. Community/Non-profit

d. Government: Federal Provincial Municipal Crown agency

e. Other

4. What kind of work do you do?

5. How long have you been using Community Counts?

More than 5 years

3-5 years 1-2 years less than 1 year

6. How often do you use Community Counts?

Daily __ Weekly __ Monthly ___ Occasionally

7. What do you use Community Counts for?

8. What benefits/outcomes/impacts have you noticed using data from Community Counts?

9. Who has benefited from your use of Community Counts?

10. Can you say what value you place on these benefits/outcomes/impacts? For example, dollar value, time saved, funding secured? [There may be others.]

11. Do you have any additional comments? 


\section{References}

Bartenberger, M., \& Grubmüller, V. (2014). The Enabling Effects of Open Government Data on Collaborative Governance in Smart City Contexts. eJournal of eDemocracy \& Open Government, 6(1), 36-48.

Bonina, C. (2013). New business models and the value of open data: definitions, challenges and opportunities. Department of Management. London School of Economics and Political Science.

Caplan, R., Davies, T., Wadud, A., Verhulst, S., Alonso, J., \& Farhan, H. New York University, (2014). Towards common methods for assessing open data: workshop report \& draft framework. Retrieved March 3, 2015, from http:/ /opendataresearch.org/sites/default/files/posts/Common Assessment Workshop Report.pdf

Charalabidis, Y., Loukis, E., \& Alexopoulos, C. (2014). Evaluating Second Generation Open Government Data Infrastructures Using Value Models (pp. 2114-2126). IEEE. http://doi.org/10.1109/HICSS.2014.267

Currie, L. (2013). The role of Canadian municipal open data initiatives: A multi-city evaluation. Master's thesis, Queen's University.

Davies, T. (2010). Open data, democracy and public sector reform: A look at open government data use from data.gov.uk. (Doctoral dissertation, Oxford Internet Institute) Retrieved from http://www.opendataimpacts.net/report/

Davies, T., \& Edwards, D. (2012). Emerging implications of open and linked data for knowledge sharing in development, IDS Bulletin 43(5), 117-127.

The European Public Sector Information Platform. (2015). The PSI scoreboard. Retrieved March 20, 2015, from http://www.epsiplatform.eu/content/european-psi-scoreboard

Francoli, M. (2011). What makes governments 'open'?.eJournal of Democracy, 3(2), 152-165.

GovLab (2016a). The OD 500 Global Network. Retrieved April 26, 2016, from http:/ /www.opendata500.com/

GovLab (2016b). Open Data's Impact. Retrieved April 26, 2016, from http:/ /odimpact.org/

Granickas, K. (2013). Understanding the impact of releasing and re-using open government data. Retrieved April 25, 2016 from http://www.epsiplatform.eu/content/understanding-impactreleasing-and-reusing-open-government-data

Howard, A. (2012). Eight open government recommendations for Canada. Retrieved March 20, 2015, from http://gov20.govfresh.com/eight-open-government-recommendations-for-canada/

Janssen, M., Charalabidis, Y., \& Zuiderwijk, A. (2012). Benefits, adoption barriers and myths of open data and open government. Information Systems Management, 29(4), 258-268.

Janssen, M., Zuiderwijk, A., (2014). Infomediary business models for connecting open data providers and users. Social Science Computer Review, 32(5), 694-711.

Johnson, P.A., \& Robinson, P. (2014). Civic Hackathons: Innovation, Procurement, or Civic Engagement? Review of Policy Research, 31(4), 349-357.

Johnson, P.A., (2016). Models of direct editing of government spatial data: Challenges and constraints to the acceptance of contributed data. Cartography and Geographic Information Science.

Kassen, M. (2013). A promising phenomenon of open data: A case study of the Chicago open data project. Government Information Quarterly, 30(4), 508-513. 
Magalhaes, G., Roseira, C., \& Strover, S. (2013). Open government data intermediaries: A terminology framework. Proceedings of the 7th International Conference on Theory and Practice of Electronic Governance. ACM, 2013.

Nam, T., \& Pardo, T. A. (2014). The changing face of a city government: A case study of Philly311. Government Information Quarterly, 31(S1), S1-S9.

Open Data Barometer (2nd Edition). (2015). Method. Retrieved March 20, 2015, from http:// barometer.opendataresearch.org/report/about/method.html

Open Knowledge. (n.d.). Open definition. Retrieved March 20, 2015, from http:/ /opendefinition.org/od/

Roberts, T. (2012). The problem with open data. Retrieved March 20, 2015, from http://www.computerweekly.com/opinion/The-problem-with-Open-Data

Roy, J. (2014). Open data and open governance in Canada: A critical examination of new opportunities and old tensions. Future Internet, 2014(6), 414-432. doi: 10.3390/fi6030414

Sieber, R. E., \& Johnson, P. A. (2015). Civic open data at a crossroads: Dominant models and current challenges. Government Information Quarterly, 32(3), 308-315.

Statistics Canada, (2015). National Household Survey - Data products, 2011. Retrieved 12 September 2015, from https://www12.statcan.gc.ca/nhs-enm/2011/dp-pd/index-eng.cfm

Statistics Canada. (2014). Population by year, by province and territory. Retrieved March 20, 2015, from

http://www.statcan.gc.ca/tables-tableaux/sum-som/101/cst01/demo02a-eng.htm

Treasury Board of Canada. (2012). Minister Clement releases Open Government Action Plan. Retrieved March 20, 2015, from http://www.tbs-sct.gc.ca/media/nr-cp/2012/0412-eng.asp

Treasury Board of Canada. (2014). Directive on Open Government. Retrieved March 20, 2015, from http://www.tbs-sct.gc.ca/pol/doc-eng.aspx?id=28108

Ubaldi, B. (2013). Open Government Data: Towards Empirical Analysis of Open Government Data Initiatives. OECD Working Papers on Public Governance, No. 22, OECD Publishing.

Veljković, N., Bogdanović-Dinić, S., \& Stoimenov, L. (2014). Benchmarking open government: An open data perspective. Government Information Quarterly, 31(2), 278-290.

Wadud, A. (2014). Open data and the United Nations: Experts reflect on current open data challenges within the UN and outline a path forward. Retrieved 20 March, 2015, from http://thegovlab.org/open-data-and-theunited-nations-experts-reflect-on-current-open-data-challenges-within-the-un-and-outline-a-pathforward/

Yu, H., \& Robinson, D. G. (2012). The new ambiguity of "open government". UCLA Law Review Discourse, 59, 178-208.

Zuiderwijk, A., \& Janssen, M. (2013). Open data policies, their implementation and impact: A framework for comparison. Government Information Quarterly, 31(1), 17-29.

\section{About the Authors}

Mavis Chan is a recent graduate of the Faculty of Environment at the University of Waterloo, in Waterloo, Ontario. Research for this paper was conducted during her co-op placement at Nova Scotia Community 
Counts as Open Data Research Assistant, under the supervision of Malcolm Shookner. Her research interests include open data and governance, youth voter engagement, and sustainable energy policy.

Dr. Peter Johnson is an Assistant Professor in the Department of Geography and Environmental Management at the University of Waterloo, in Waterloo, Ontario. His research seeks to understand how governments, citizens, and private companies share information through geospatial technology, including open data, the Geoweb, social media, mobile devices, and the process of crowdsourcing. Recent projects have focused on understanding the value of government open data, the integration of volunteered geographic information in government, Geoweb platform development, and mobile application testing and evaluation

Malcolm Shookner was the Chief Statistician at Nova Scotia Community Counts at the Nova Scotia Department of Finance and Treasury Board, in Halifax, Nova Scotia from 2007-2015.

\section{Acknowledgements}

The authors would like to acknowledge support from Geothink.ca and the Social Sciences and Humanities Research Council of Canada (SSHRC). 